\title{
O DEBATE DO DESENVOLVIMENTO NA TRADIÇÃO HETERODOXA BRASILEIRA*
}

\author{
Carlos Pinkusfeld Bastos ${ }^{* *}$
}

\author{
Júlia Galarza d'Avila ${ }^{* *}$
}

\begin{abstract}
RESUMO O presente trabalho tem como objetivo resgatar o debate sobre desenvolvimento econômico dentro da tradição heterodoxa brasileira. São examinadas as teorias originais da acumulação cepalina e a forma como essas teorias foram depois utilizadas por Furtado para avançar suas hipóteses de estagnação e mais especificamente sua teoria do subdesenvolvimento. Apresentamos algumas críticas sobre a hipótese da estagnação tendo como base o trabalho de Conceição Tavares e Serra, mostrando como a tradição heterodoxa brasileira passou e incorporar o princípio da demanda efetiva em seus modelos de crescimento. Essa mudança teórica é o fundamento da chamada Escola da Unicamp. Utilizamos a discussão de ambas as abordagens para avançar na análise da interação entre distribuição de renda e desenvolvimento segundo diferentes abordagens de acumulação: a leitura clássica e a abordagem da demanda efetiva.
\end{abstract}

Palavras-chave: história do pensamento econômico; desenvolvimento econômico; acumulação de capital; Celso Furtado

Código JEL: B20, O14

\section{THE DEBATE ON DEVELOPMENT WITHIN}

THE BRAZILIAN HETHERODOX TRADITION

ABSTRACT This paper is an attempt to revisit the debate on economic development within the Brazilian heterodox tradition. We examine some aspects of the original

* Artigo recebido em 8 de maio de 2008 e aprovado em 15 de junho de 2009.

** Professor adjunto da Faculdade de Economia da Universidade Federal Fluminense, e-mail: pinkusfeld@gmail.com.br

*** Economista do Banco Regional de Desenvolvimento do Extremo Sul (BRDE), e-mail: juliagalarza@ gmail.com 
Cepalâ€ $€^{\mathrm{TM}}$ s accumulation theory and how Celso Furtado contributed to this approach through his stagnation hypothesis, and more importantly, with his particular Underdevelopment Theory. After this we present some criticism on the stagnation hypothesis and based, on the work by Conceição Tavares and José Serra, show how the Brazilian heterodox tradition incorporated the Principle of Effective Demand in its growth models. This theoretical shift defines the basic thrust of the Unicamp School. This basic discussion is used to analyze the interaction between income distribution and development. It is shown that different approaches, classical against effective demand, have different roles for the causal connection between these two variables.

Key words: economic development; history of economic thought; capital accumulation; Celso Furtado 


\section{INTRODUÇÃO}

O cenário político e econômico mundial das primeiras décadas do século XX foi crucial para o surgimento da economia do desenvolvimento como um tópico autônomo dentro da teoria econômica. A economia clássica tinha como objeto central o desenvolvimento; no entanto, este não havia se firmado como uma disciplina distinta, com um corpo teórico próprio. O período que se segue ao da hegemonia teórica clássica, com o surgimento da ortodoxia neoclássica, teve como uma de suas características o abandono da problemática do desenvolvimento econômico em favor da análise da alocação, tendo como suposto a escassez e como mecanismo fundamental o princípio da substituição.

O fim da chamada Era Liberal do século XIX, com a crise de 1929, e as experiências, a partir daí, vivenciadas por vários países no período que vai do fim da Primeira Grande Guerra até a Segunda Guerra Mundial foram os propulsores do debate profundo sobre o desenvolvimento econômico, que se assistiria ao final da década de 1940 e na década de 1950. Esse período é chamado por Meier (1984) de "the pioneering period" para a nova economia do desenvolvimento, que tem como foco os problemas de desenvolvimento da Ásia, África e América Latina. O desenvolvimento econômico como tema de debate acadêmico foi uma resposta a uma situação histórica particular. Esse debate se torna ainda mais premente, demandando a proposição de políticas aplicadas específicas, devido ao estabelecimento da descolonização e da Guerra Fria no pós-guerra. As ideias desenvolvimentistas respondiam a uma necessidade sociopolítica de propor medidas que favorecessem o crescimento acelerado, ou seja, de catch up, a países "novos" ou não, dentro da luta por supremacia político-ideológica entre Estados Unidos e URSS.

Assim, as décadas de 1940 e 1950 marcam uma mudança na perspectiva intelectual até então dominante, com a emergência de um novo consenso, o "consenso do desenvolvimento", que prevalecerá no cenário econômico e ideológico até os anos 1970. Ilustrativa desse "consenso" foi a declaração, por parte das Nações Unidas (ONU) e do governo dos Estados Unidos, da década de 1960 como a "década do desenvolvimento". A adoção de políticas desenvolvimentistas recebeu o apoio explícito de órgãos internacionais oficiais e as Comissões Regionais da ONU assumiram um papel ativo no exame dos problemas do desenvolvimento, sendo a Comissão Econômica para a 
América Latina (Cepal), criada em 1948, a comissão mais proeminente. (Meier, 1984).

É nesse centro que se formam intelectualmente os principais economistas brasileiros que a partir da década de 1950 passaram a exercer papel central no debate e na proposição de política econômica dentro de uma perspectiva heterodoxa.

O pioneiro e fundador dessa tradição foi Celso Furtado. Furtado não apenas teve contribuição central no debate intelectual desde a década de 1950, produzindo, entre outras obras, o clássico Formação econômica do Brasil, como participou ativamente como policy maker através do relatório Cepal - BNDES, da fundação da Sudene e da proposta e início da execução do Plano Trienal em 1963. Sua carreira como policy maker foi interrompida pelo golpe militar de 1964, mas sua produção acadêmica continuou até a morte. Dentro dessa tradição heterodoxa brasileira podemos também destacar a economista Maria da Conceição Tavares que, sendo formada pela Cepal, publicou obras centrais dentro dessa tradição, como o livro Da substituição de importações ao capitalismo financeiro: ensaios sobre a economia brasileira, mas que no decorrer do seu percurso intelectual avançou sua reflexão incorporando novos paradigmas teóricos que acabaram por conformar a interpretação da economia brasileira da Escola da Unicamp.

O pensamento heterodoxo desenvolvimentista latino-americano em geral, e brasileiro em particular, nasce das ideias e do ambiente intelectual desenvolvimentista mundial dos anos 1940 e evolui com a incorporação de outras contribuições heterodoxas, principalmente de autores de alguma forma ligados à tradição de Cambridge, como Kalecki, Kaldor, Joan Robinson $^{1}$ e outros, como Steindel, Labini, Minsky. Essa trajetória, entretanto, não foi linear, envolvendo debates, controvérsias, revisões de posições por diferentes autores e mesmo divergências nunca sanadas. Infelizmente, a reação liberal, que se solidificou a partir da década de 1990, contrapôs-se a essa tradição rotulando-a de forma caricata como "intervencionista", "estatista", "protecionista". Tais qualificativos, embora não sejam necessariamente incorretos, além de carregados de juízos de valores supostamente negativos, são nocivos à tradição heterodoxa ao homogeneizá-la, através de palavraschave, ofuscando debates e divergências dentro desse campo que, em grande medida, permanecem atuais. O objetivo deste trabalho é revisitar um desses 
grandes debates da tradição heterodoxa brasileira: o debate sobre a desaceleração do crescimento econômico no início dos anos 1960 que estava por trás das ideias, então percebidas, como de esgotamento do modelo de substituição de importações, tendência à estagnação e subdesenvolvimento (no conceito furtadiano, como precisaremos à frente). Esse debate e, em alguns aspectos, sua superação envolvem a compreensão das próprias mudanças analíticas do pensamento heterodoxo brasileiro, bem como a discussão de temas até hoje centrais para o desenvolvimento, como a relação entre crescimento e distribuição de renda.

Tais tópicos serão desenvolvidos com uma discussão inicial sobre os fundamentos clássicos da teoria do desenvolvimento dos anos 1950. Na seção seguinte discute-se como essa abordagem se relaciona à interpretação cepalina, e principalmente furtadiana, da economia brasileira. Apresentamos também a crítica de Conceição Tavares a essa leitura e sua contribuição para a formação da Escola da Unicamp. Na última seção são feitas algumas observações buscando sintetizar as interpretações divergentes apresentadas no decorrer do trabalho.

\section{A tEORIA DO DESENVOLVIMENTO CEPALINO E O PARADIGMA CLÁSSICO}

A teoria do desenvolvimento nascida nos anos 1940 é caracterizada como a teoria econômica com oferta ilimitada de mão de obra. A expressão está inclusive no título do trabalho seminal de Arthur Lewis em 1954, O desenvolvimento econômico com oferta ilimitada de mão-de-obra, o qual lhe valeu um Prêmio Nobel em 1979. Esse era um ponto central da sua argumentação, sendo claramente enunciado logo nas duas primeiras páginas de seu artigo, questionando, assim, o pressuposto básico da teoria neoclássica, qual seja, o princípio da escassez, ou, neste caso específico, que existe limitação na oferta de mão de obra. ${ }^{3}$ Essa observação empírica já havia sido constatada por diversos autores, ${ }^{4}$ mas Lewis explicitou suas consequências para mostrar como a teoria neoclássica ${ }^{5}$ era inadequada para vários países que apresentavam excedente de mão de obra. A partir das hipóteses de oferta ilimitada de mão de obra, remunerada com salários de subsistência, e de que a produção aumenta com o decorrer do tempo através da crescente acumulação de capital, Lewis formulou um modelo seguindo a tradição clássica. 
O nível de subsistência é que determina o preço do trabalho e, nas palavras do autor, “a oferta de trabalho é, portanto, 'ilimitada' porquanto a oferta, a este preço, excede a demanda” (Lewis, 1954, p. 409). O nível de subsistência define-se através de uma convenção acerca do mínimo necessário para subsistir ou pode ser determinado como o produto médio per capita na agricultura mais uma certa margem.

O setor capitalista ${ }^{6}$ é definido como a parte da economia que utiliza capital reproduzível e visa ao lucro, com trabalhadores assalariados, enquanto o setor de subsistência é toda a parte da economia que não utiliza capital reproduzível e o objetivo principal da atividade econômica é a manutenção do consumo, como seria o caso de camponeses e empregados por conta própria. $^{7}$ O produto per capita no setor de subsistência é menor do que no setor capitalista, pois "não é frutificado pelo capital”, daí chamar-se improdutivo (Lewis, 1954, p. 414).

Dessa forma, o setor de subsistência estabelece o mínimo, mas os salários no setor capitalista serão maiores e, de acordo com a disponibilidade de capital, mais trabalhadores podem ser levados do setor de subsistência para o capitalista, elevando o produto per capita. A mão de obra será empregada no setor capitalista até o ponto em que o salário se torne igual à produtividade marginal. Assim, a teoria do desenvolvimento se apresenta como uma crítica limitada à ortodoxia neoclássica, um “caso particular” teórico respondendo a condições histórico-empíricas específicas cuja validade se encerra na medida em que essas peculiaridades são eliminadas pelo próprio desenvolvimento econômico.

A heterodoxia latino-americana, que se funda com os relatórios pioneiros de Raul Prebisch para a Cepal (Prebisch, 1949), herda dessa abordagem da sua estrutura teórica geral. ${ }^{8}$ Dentro dessa estrutura está a determinação da renda pela Lei de Say. Essa característica, em termos macroeconômicos, se expressa pela relação causal poupança-investimento: uma maior poupança implicará um maior nível de investimento. Nessa abordagem teórica o produto, ou seu crescimento, não é restrito pela demanda, e sim pela oferta. Economias cresceriam menos porque a poupança potencial máxima é limitada, gerando uma restrição ao investimento e, consequentemente, ao crescimento mais acelerado do produto potencial. 
No modelo de Lewis há uma visão "otimista” das possibilidades do crescimento seguindo a abordagem clássica. Dado que os salários são determinados basicamente pelo nível de subsistência, o emprego em setores modernos de mais elevada produtividade gerariam um montante de lucros e, consequentemente, poupança potencial ampliados. A ruptura da armadilha da não industrialização liberaria forças, em termos de elevação da poupança através do crescimento da produtividade do trabalho não acompanhada pelos salários. Essa poupança ampliada seria capaz de acelerar o crescimento econômico, terminando por eliminar o mercado dual de trabalho, ou o próprio excedente estrutural da mão de obra.

Ainda que seguindo as premissas teóricas fundamentais contidas no trabalho de Lewis, alguns autores centrais na teoria do desenvolvimento, como Rosenstein-Rodan e principalmente Nurkse, entendem que a ruptura do "círculo vicioso" de baixa produtividade, reduzidas dimensões do mercado e baixa acumulação, acontece com o estabelecimento de um conjunto, ou bloco de investimentos, que seja capaz de gerar fortes externalidades com impactos positivos sobre as decisões de investimento individuais (ver Nurkse, por exemplo, 1951 e 1953).

No pensamento cepalino, a despeito da sua clara filiação clássica, tal otimismo é desde o início mitigado pela hipótese de que o excedente gerado no setor capitalista da economia pode não se tornar poupança-investimento dado o excessivo consumo capitalista, ou, mais geralmente, o consumo conspícuo das minorias de renda mais alta. Esse consumo das elites se basearia nos padrões de consumo, ou culturais, dos países de renda per capita mais elevada. ${ }^{9}$ Esse é um ponto central para a reflexão de Furtado e vai perpassar sua obra em vários momentos, quase como um guia condutor de sua crítica ao padrão de desenvolvimento implantado no Brasil a partir dos anos 1950.

Antes de avançar, entretanto, deve-se anotar que a preocupação cepalina quanto às possibilidades de sucesso do processo de industrialização na América Latina não se cingia à questão de falta de poupança por excessivo consumo de luxo. ${ }^{10}$ Uma outra limitação ao crescimento econômico seria uma relação capital/produto excessivamente elevada. Com uma relação capital/ produto muito alta, um mesmo montante de poupança-investimento resultaria em uma taxa de crescimento menor. As fórmulas a seguir ${ }^{11}$ nos permitem explicitar essas duas relações com maior clareza: 


$$
\begin{aligned}
& Y^{*}=K \frac{1}{v} \\
& \Delta Y^{*}=\frac{\Delta K}{v}=\frac{I}{v} \\
& \frac{\Delta Y^{*}}{Y^{*}}=\frac{I}{Y^{*}} \frac{1}{v}=\frac{S}{Y^{*}} \frac{1}{v} \\
& g=\frac{s}{v}
\end{aligned}
$$

onde $v$ é relação capita/produto, $s$ a propensão a poupar e $g$ a taxa de crescimento do produto correspondente à plena utilização de capital, ou taxa garantida.

Supondo, por simplificação que os trabalhadores não poupam:

$$
\begin{aligned}
& s=s_{k} \frac{P}{Y} \\
& s=s_{k}(1-w)
\end{aligned}
$$

onde $s_{k}$ é a propensão a poupar dos capitalistas, $P$ os lucros e $w$ a participação dos salários na renda. Substituindo (2) em (1), obtêm-se:

$$
\begin{aligned}
& g=\frac{s_{k}(1-w)}{v}=s_{k}(1-w) \frac{Y}{K} \\
& g=s_{k}(1-w) R
\end{aligned}
$$

Um maior consumo "capitalista" implicaria um menor $s_{k}$ e, como vemos em (3), consequentemente, um menor crescimento econômico. Podemos observar também que uma maior relação capital/produto, ou alternativamente uma menor Taxa Máxima ( $\mathrm{R}$ ), também causaria uma redução do crescimento econômico. Raul Prebisch, em seus estudos pioneiros, já apontava para o problema de uma relação capital/produto elevada como entrave ao crescimento econômico, ou uma desvantagem dos países não industrializados em face dos países desenvolvidos:

Nos países desenvolvidos a técnica produtiva exige um alto grau de capital per capita, mas o desenvolvimento paulatino da produtividade, que se deve justamente a essa técnica, permitiu que esses países tivessem elevada renda per capita, mediante a qual realizaram a poupança necessária para formar o 
capital requerido. Inversamente, na maior parte dos países latino-americanos, a poupança é escassa, em decorrência do baixo nível de renda. Quando os que hoje são grandes centros industriais estavam em situação comparável à que agora se apresenta nos países periféricos, e quando a renda per capita era relativamente pequena, técnica produtiva também exigia um capital per capita relativamente exíguo (Prebisch, 1949, p. 163).

Uma vez entendido o esquema analítico clássico seguido pelos autores da teoria do desenvolvimento que surge a partir da década de 1940, na qual se inclui a reflexão teórica de autores latino-americanos como Prebisch e Furtado, podemos ver como se relacionam acumulação, seus supostos problemas e limitações, e distribuição de renda.

\section{ACUMULAÇÃO, ESTAGNAÇÃO, SUBDESENVOLVIMENTO E DISTRIBUIÇÃO DE RENDA}

Como lembrado anteriormente, Furtado não apenas participou da formulação da teoria do desenvolvimento na América Latina como também teve atuação destacada como policy maker diretamente ligado ao executivo e formulador de planos de desenvolvimento quando ligado à Cepal. ${ }^{12}$ Entretanto, na entrada dos anos 1960, ou seja, após o bem-sucedido, pelo menos em termos de cumprimento de suas metas quantitativas gerais e setoriais, período do Plano de Metas, Furtado adota um tom mais "pessimista" em sua reflexão. Referimo-nos, especificamente, à hipótese central da teoria do desenvolvimento, de que a industrialização seria capaz de eliminar a dualidade básica da economia, com a absorção do excedente estrutural de mão de obra no setor moderno e de maior produtividade per capita da economia. Na descrição de Furtado (1963, p. 180):

... a resultante foi quase sempre a criação de estruturas híbridas, uma parte das quais tendia a comportar-se como um sistema capitalista, a outra, a manter-se dentro de uma estrutura preexistente. Este tipo de economia dualista constitui, especificamente, o fenômeno do subdesenvolvimento contemporâneo. O subdesenvolvimento é, portanto, um processo histórico autônomo e não uma etapa pela qual, necessariamente, tenham passado as economias que já alcançaram grau superior de desenvolvimento.

Deve-se destacar que com essa formulação Furtado rompe com uma leitura linear, rostowiana, do desenvolvimento, ou seja, que este seria compos- 
to de etapas vencidas paulatinamente até o destino final de eliminação da heterogeneidade dual. O subdesenvolvimento, nessa formulação de Furtado, é uma estrutura estável que conviveria e, mais do que isso, seria uma consequência do padrão de desenvolvimento adotado no Brasil desde os anos 1950. É importante destacar que essa visão pessimista quanto às perspectivas da continuação do processo de desenvolvimento no início dos anos 1960 era compartilhada por outros autores da tradição cepalina, como Maria da Conceição Tavares.

Tavares (1963) identifica perda de dinamismo, entre 1958 e 1961, nas indústrias de base, principalmente nas indústrias mecânicas e de material elétrico, o que estaria relacionado ao avanço do processo de substituição de importações para faixas de maior intensidade de capital e à redução da reserva interna do mercado para substituição.

Segundo a autora, “...o modelo de desenvolvimento recente conduziu a economia brasileira a um dos tipos mais acabados de economia dual dentro da própria América Latina" (1963, p. 110). Há não só desníveis absolutos de produtividade como uma tendência à disparidade aumentar.

Tal tendência decorre do avanço da industrialização para faixas com densidade de capital mais alta e/ou a introdução de técnicas poupadoras de mão de obra, o que impediu que houvesse uma maior absorção de mão de obra e do fato de a estrutura produtiva do setor primário não ter se alterado, o que impossibilitou a incorporação da população ao mercado consumidor.

Tavares também prossegue na problemática de Furtado (e Prebisch) citada anteriormente da elevada relação capital/produto derivada do tipo de tecnologia adotada, o que representa um grande esforço de acumulação com pouca geração de emprego, ao longo do processo de crescimento. Além disso, surgem problemas quando o processo avança para faixas que exigem maior escala e são de maior complexidade tecnológica, o que representa um freio à diversificação e à integração do sistema produtivo industrial, dados o montante de capital necessário, a dimensão do mercado e o know how requeridos.

A transferência da população das áreas rurais para as urbanas não teve o mesmo sentido do modelo de Lewis e de outros modelos históricos de alguns países desenvolvidos, ${ }^{13}$ tendo crescido a população marginal e o desemprego disfarçado nas cidades. O setor industrial aumentou seu grau de 
diversificação e nível de produtividade, mas o estágio de desenvolvimento alcançado não é equilibrado.

Em termos sociais, os desequilíbrios se agravaram no processo de desenvolvimento, tendo aumentado a população marginal e o desnível de renda da população ocupada entre o setor primário e o secundário, o que se deve, em grande parte, ao fato de os setores dinâmicos da economia não terem absorvido a população em idade economicamente ativa em ritmo satisfatório. Ao mesmo tempo, tem-se um desequilíbrio social dentro da própria região mais desenvolvida, indicado pela concentração econômica no setor industrial. ${ }^{14}$

Pode-se ver pelos argumentos listados que havia uma clara percepção por parte de importantes autores da tradição cepalina de que o período de crescimento acelerado do início dos anos 1950 havia no mínimo chegado a pontos de estrangulamento e desequilíbrios macroeconômicos, setoriais e sociais. Essa percepção inspirou em Furtado o nascimento de conceito teórico particular: o subdesenvolvimento. Entretanto, esse mesmo autor, em seu livro Subdesenvolvimento e estagnação na América Latina, avança uma hipótese mais radical: a de que o processo de desenvolvimento como levado a cabo até então levaria inexoravelmente à estagnação econômica.

A crítica teórica a essa tese de Furtado foi feita em detalhe por Tavares e Serra (1970, p. 159-167). Utilizaremos aqui apenas uma formulação muito simples, a fim de mostrar inicialmente alguns problemas internos ao argumento furtadiano.

Após essa radicalização com a formulação da tese estagnacionista, Furtado, de certa forma, retorna a uma formulação mais "branda" que dá sustentação à sua tese sobre subdesenvolvimento, como será mostrado à frente.

O ponto inicial do argumento estagnacionista de Furtado é a já citada elevação da relação capital/produto à medida que o processo de substituição de importação vai atingindo seus estágios mais complexos. ${ }^{15}$ Como se pode verificar na equação (3) citada, uma elevação da relação capital/produto (ou uma redução da produtividade do capital), uma vez mantidas a distribuição de renda e a propensão a poupar dos capitalistas, resultaria em uma menor taxa de crescimento econômico.

A primeira qualificação que deve ser feita a essa hipótese é anotar que a relação capital/produto normal ou de longo prazo ${ }^{16}$ é um resultado da interação entre duas variáveis, as relações capital per capita e produto per capita: 


$$
\frac{Y}{K}=\frac{Y}{L} \frac{L}{K}
$$

onde $L$ é a mão de obra.

Pode-se observar que para que $Y / K$ diminua, ou para que a relação capital/produto se eleve, é necessário que se faça uma hipótese muito particular entre os ganhos de produtividade do trabalho e a maior mecanização da economia, ou seja, é necessário que os ganhos de produtividade não compensem a maior utilização de capital por trabalhador.

Mas, mesmo supondo-se que isso ocorra, não decorre daí uma redução do crescimento da economia, dentro dos limites teóricos da teoria clássica do investimento que norteia a reflexão furtadiana.

Na argumentação de Furtado (1965), o autor parte do conjunto de circunstâncias, já descritas, que supostamente levariam à elevação da relação capital/produto da economia. ${ }^{17}$ Como vemos na fórmula a seguir, a elevação da relação capital/produto tem como contrapartida um aumento da produtividade do trabalho. Dado que $b$, o salário real, em um modelo tradicional da teoria do desenvolvimento aqui analisada, é constante e exogenamente determinado, podem-se ver os dois efeitos contrários de uma maior mecanização da economia na expressão para a taxa de lucro em (5): ${ }^{18}$

$$
r=\frac{Y}{K}\left[1-b \frac{L}{Y}\right]
$$

Na realidade, dada uma taxa de salário constante, à medida que se aumenta a capitalização de uma economia ocorre um aumento na massa de lucros em face da parcela dos salários, ou seja, uma mudança na distribuição de renda que tem um efeito positivo sobre o crescimento econômico dentro de um modelo clássico. Essa relação é explicitada na equação (3). Se multiplicarmos a taxa máxima, $\mathrm{R}$, pela fração dos lucros na renda teremos a taxa de lucro da economia, como em (6):

$$
g=s_{k} r
$$

Assim, uma elevação da relação capital/produto não tem impacto no crescimento a menos que haja uma redução da taxa de lucro na economia. 
Dada uma propensão a poupar constante dos capitalistas, a queda da taxa de lucro é a única condição para se gerar uma tendência à estagnação.

Esse fenômeno, entretanto, se insere em uma discussão muito mais ampla que o modelo furtadiano, sendo um tema extremamente controverso e pertencente à tradição marxista. A ocorrência de tal tendência prescinde de qualquer referência específica à condição periférica de uma determinada economia, ou seja, seria uma tendência inerente ao processo de acumulação capitalista. A apresentação da vasta polêmica sobre essa questão escapa inteiramente ao escopo deste trabalho, no entanto é a esta que se deve referir para situar corretamente as hipóteses estagnacionistas furtadianas.

Da apresentação anterior pode-se concluir que a hipótese da elevação da relação capital/produto está longe de ser facilmente comprovada, como sugere Furtado. Além disso, seguindo a teoria clássica da determinação do produto e dado um salário real constante, o aumento da produtividade do trabalho levaria a uma concentração de renda, sendo esta funcional no sentido de evitar a redução da taxa de crescimento econômico em função de uma possível elevação da relação capital/produto.

Essa observação é importante na medida em que o artigo de Tavares e Serra (1970) não apenas apresenta uma crítica teórica à hipótese de Furtado. Tavares e Serra, no início dos anos 1970, estão não apenas fazendo uma crítica abstrata à hipótese estagnacionista de Furtado, mas também explicando o fato de ter ocorrido exatamente o oposto do previsto por esse autor: a forte aceleração do crescimento econômico no período do milagre econômico.

Entretanto, ao fazerem tal crítica, o fundamento clássico da teoria do investimento, ou seja, aquela que apresenta uma relação direta entre concentração de renda e maior acumulação, é abandonado. Esses autores utilizam-se de um instrumental analítico kaleckiano, ou de demanda efetiva, em que a trajetória do crescimento deve ser explicada pelo comportamento das variáveis de demanda e em que a restrição ao crescimento se dá pela eventual debilidade dessas variáveis, e não uma restrição pelo lado da poupança. Assim, a relação entre concentração de renda e crescimento não mais se determina de forma direta e unívoca, na qual a primeira é condição lógica para explicar o segundo, seja em relação à sua aceleração (hipótese da poupança forçada), seja na crítica à estagnação (hipótese da elevação da relação capital/produto). 
Nesse debate reside um ponto central cujo esclarecimento nos parece importante não apenas em uma perspectiva do estudo da evolução da interpretação econômica brasileira, mas por iluminar um tema recorrente, e algumas vezes malcompreendido, que é a relação entre concentração de renda e crescimento econômico no Brasil.

A recuperação do milagre se fez com concentração de renda, ainda que esta tenha sido resultado de uma política anti-inflacionária que usou o salário nominal e, consequentemente, o salário real, como variável distributiva a ser controlada para reduzir a inflação gradualmente. Entretanto, tal concentração de renda, ao contrário da interpretação usual da poupança forçada, ${ }^{19}$ ou seguindo logicamente o modelo de Furtado (1965), não é funcional por gerar uma poupança necessária para um crescimento mais acelerado. Dentro da perspectiva do princípio da demanda efetiva, uma maior concentração de renda, efeito colateral da política de estabilização adotada e do novo balanço de forças políticas do regime militar, pode ter um efeito circunstancial, ou conjuntural, de reforçar a adequação da estrutura da oferta e a demanda efetiva, mas não determina através da elevação das taxas de lucro e da poupança agregada o investimento em máquinas e equipamentos. Para analisar essa eventual adequação deve-se retroceder até o período de industrialização acelerada do final da década de 1950.

Na implantação do Plano de Metas optou-se pela industrialização substitutiva, que refletia uma distribuição de renda regressiva existente, dandose prioridade a certas indústrias de bens de consumo duráveis mais sofisticadas tecnologicamente. Assim, assistiu-se à implantação de unidades industriais que tinham como exigência tecnológica uma escala mínima, o que normalmente cria, e efetivamente criou, uma capacidade instalada à frente da demanda corrente. Isso requereria um crescimento persistente da demanda agregada, e particularmente do poder de compra dos setores de classe média e alta. Essa evolução do poder de compra ficou comprometida pela exacerbação da desaceleração cíclica esperada do início dos anos 1960 em consequência da grave crise econômica e política que se instalou a partir de $1961 .{ }^{20}$

Assim, em um momento em que tal estrutura de oferta se encontra operando com uma capacidade ociosa elevada, como ocorreu no início da segunda metade dos anos 1960, não só em consequência dos problemas eco- 
nômico-políticos pré-1964 como também em razão de algumas medidas restritivas dos primeiros governos militares, ${ }^{21}$ uma mudança na direção de maior concentração da distribuição funcional/pessoal de renda pode ter uma contribuição positiva "circunstancial" à adequação da composição de demanda e oferta da economia.

Entretanto, o ponto mais importante da contribuição de Tavares e Serra (1970) foram, certamente, o destaque dado às reformas financeiras implementadas pelo regime militar e o impacto positivo desse fato sobre os componentes de demanda autônoma como consumo de bens duráveis e construção civil. ${ }^{22}$ Nas palavras dos autores, ainda que se referindo apenas à demanda de duráveis:

A política do novo governo militar criou condições para uma reorganização do esquema redistributivo "conveniente" ao sistema, ... [e]sta redistribuição teve início primeiro ao nível do gasto, mediante novos esquemas ampliados de financiamento de bens duráveis... (Tavares e Serra, 1970, p. 201).

Claramente, essa é uma inflexão teórica, já que a recuperação cíclica se faz pelo lado do crédito/demanda autônoma, e não baseada em numa maior poupança, que teria surgido de uma limitação ao consumo induzido em consequência da queda dos salários.

Temos um caso de superposição histórico-teórica no qual não apenas o padrão de acumulação está em transição (com o crescimento do crédito para consumo de duráveis, por exemplo), como, também, a própria reflexão teórica de alguns autores, como é o caso de Conceição Tavares.

Apesar de o ensaio "Além da estagnação", de 1970, já representar uma ruptura com relação à visão estagnacionista, a sua interpretação geral seguia filiada à concepção de que a industrialização se dava através dos impulsos gerados pelo estrangulamento externo, em um processo de substituição de importações. Uma citação um pouco extensa, mas central, esclarece como a partir de Tavares (1974) desenvolve-se uma nova abordagem teórica, a qual resultará em nova periodização e denominação para o processo de desenvolvimento no Brasil, que apresenta claramente as mudanças no pensamento da autora radicalizando a interpretação da dinâmica econômica da industrialização brasileira como inserida dentro de um mesmo marco teórico geral da demanda efetiva: 
Assim, minha própria análise do período de industrialização do pós-guerra, principalmente para a etapa chamada "intensiva”, só se sustenta teoricamente em termos formais, como correspondente a um período do processo de substituição de importações, se for tomada exclusivamente do ponto de vista da dinâmica contraditória dos estrangulamentos sucessivos do setor externo.

A abordagem teórica do processo "parcial e fechado" de desenvolvimento em seus aspectos relevantes e corretos sobre problemas da estrutura de crescimento e diversificação "vertical” do mercado não se deriva, porém, analiticamente, da dinâmica "externa-interna", como na proposição originária e central do pensamento cepalino.

Esta derivação não me parece, hoje, "viável" teoricamente, à luz de uma reflexão mais cuidadosa sobre os "modelos" ou visões de dinâmica econômica. Com efeito, todas as teorias dinâmicas requerem algum esquema "endógeno" de movimento, como suporte analítico, a partir do qual o seu modo de funcionamento possa ser "aberto" ou expandido à totalidade do sistema, dependendo da abordagem aos problemas a ser feita do ponto de vista da periferia ou do centro.

Nossa proposição alternativa (...) privilegia, pois, os aspectos internos do movimento de acumulação de capital, pondo ênfase no andamento cíclico característico de estruturas industriais que incorporam empresas nacionais, públicas e estrangeiras com poder desigual de acumulação. A partir dessa análise é que se podem compreender de forma integrada os problemas de "abertura externa" da economia brasileira e de sua articulação "dependente" com o sistema internacional (Tavares, 1974, p. 101-102).

Conforme a autora, as interpretações baseadas na ideia de substituição de importações ou na ideia de dependência não “...são suficientes para esclarecer satisfatoriamente a especificidade histórica e teórica do desenvolvimento" (Tavares, 1974, p. 110). A denominação de substituição de importações é abandonada por ser considerada

...completamente inadequada do ponto de vista analítico, ainda que formalmente ela possa ser adotada à medida que o coeficiente importado da oferta final de bens industriais esteve caindo, mesmo para as indústrias de bens de consumo duráveis, que esgotam a reserva de mercado preexistente em seu primeiro e curto período de expansão (Tavares, 1974, p. 114).

A inadequação da expressão "substituição de importações" para descrever o processo de industrialização brasileiro é ainda mais acentuada na medida em que ela é contraposta, criticamente, por intérpretes liberais, ao cres- 
cimento liderado pelas exportações, que tem como suposto exemplo de maior sucesso a Coreia do Sul. Tal dicotomia é inteiramente inadequada, já que tanto na Coreia houve um processo de substituição de importações como no Brasil, a partir dos anos 1970, ocorreu forte expansão da exportação de industrializados. Os componentes de demanda autônomo-centrais a cada processo de acumulação refletem tanto condições estruturais de cada país quanto suas diferentes inserções geoeconômicas e geopolíticas. ${ }^{23}$

Essa mudança de paradigma analítico não apenas é importante para a análise das perspectivas do desenvolvimento como também para uma reinterpretação, ou reperiodização, da industrialização do Brasil, que se refletiu na obra clássica da Escola da Unicamp, O capitalismo tardio, de João Manoel Cardoso de Mello, 1975.

Entretanto, em relação aos objetivos deste trabalho, o que se deve sublinhar é que a mudança de perspectiva teórica muda também o foco analítico para outras questões, como: financiamento, estrutura produtiva em nível microeconômico e sua capacidade de gerar processos de inovação de produto com consequente diferenciação do consumo das classes média e alta, capacidade de geração de progresso técnico-endógeno como força determinante do investimento endógeno etc.

Assim, fica clara a direção tomada por Tavares em seus estudos posteriores, que buscam examinar em detalhe questões financeiras, aí incluindo a condições de financiamento do estado e da capacidade inovativa das empresas nacionais, esta por sua vez também ligada à sua escala de produção e capacidade financeira (ver Miranda e Tavares, 1999).

Esse desenvolvimento teórico-interpretativo que se consubstancia na chamada Escola da Unicamp nunca foi acompanhado por Furtado em sua obra a partir de 1970, demarcando-se uma clara cisão entre representantes centrais do pensamento heterodoxo no Brasil. Furtado (1972) em grande medida acaba por subscrever o papel exercido pelo crédito na recuperação do milagre econômico, mas sua interpretação central continua apontando para a inviabilidade da combinação entre desenvolvimento econômico na periferia e o padrão de consumo de uma parcela populacional minoritária com participação desproporcionalmente elevada na renda nacional.

Esse tipo de preocupação chega a um grau de "radicalidade" bem mais amplo em Furtado (1974), ao criticar o próprio conceito de desenvolvimen- 
to econômico à luz das limitações físicas/ecológicas do planeta. Furtado critica o relatório do Clube de Roma por partir de uma premissa equivocada para avançar suas previsões pessimistas quanto ao esgotamento futuro dos recursos naturais. Para ele, a premissa equivocada é a possibilidade de o padrão de desenvolvimento dos países avançados ser estendido aos países pobres, ou seja, uma expansão linear do uso de recursos naturais pela maioria dos países a partir do padrão de consumo dos países desenvolvidos. Ainda nessa clave menos economicista, Furtado, em algumas obras de maturidade, como em 1984 e 2002, argumenta que a ruptura desse padrão de consumo fisicamente inviável só se fará com mudanças drásticas e profundas político-culturais.

Em termos de mecanismos estritamente econômicos em uma obra dos anos 1960, Teoria e política do desenvolvimento econômico, mas que foi reeditada e revista pelo próprio autor em 2000, mantém-se o uso da palavra estagnação, ainda que não exatamente como o fenômeno da cessação do crescimento econômico, mas como a sua não aceleração ou um certo "entorpecimento" que resultaria de uma "baixa eficiência dos investimentos ... [com o] processo de industrialização reduz[indo] seu poder de transformação das estruturas sociais" (p. 294).

Furtado tenta, assim, mostrar como os padrões de oferta e demanda da economia brasileira se reforçam para gerar uma dinâmica de desaceleração do crescimento econômico. Entretanto, o lado da demanda é entendido por ele como o padrão de consumo existente (e não como o montante de bens demandado). A estrutura produtiva correspondente a tal padrão teria impacto sobre a demanda agregada através da baixa capacidade de geração de emprego e renda. A limitada geração do emprego deprimiria os salários com impactos concentradores sobre a distribuição de renda e crescimento econômico, e, finalmente, sobre a própria estrutura de oferta, compatível com tal distribuição de renda. Essas ligações fechariam os nexos do seu modelo de "causação circular" (Furtado, 1965, p. 86).

Como visto anteriormente, aspectos de demanda estão nas economias modernas ligados a padrões de consumo diversificado e à capacidade de financiamento, ou fornecimento de crédito, de tal consumo, como sublinhado pela obra de Conceição Tavares a partir dos anos 1970. Ademais, a hipótese de uma persistente elevação da relação capital, produto, além de 
depender de hipóteses muito particulares sobre progresso técnico (ver equação 4) supõe, que setores produtores de bens de luxo sejam necessariamente mais capital intensivo que os de bens de consumo popular. A generalização dessa hipótese parece problemática, existindo uma série de contraexemplos facilmente enumeráveis. Como exemplo poderíamos citar que o consumo de luxo moderno incorpora cada vez mais bens "artesanais", ou personalizados, com uso intensivo de mão de obra. Já alguns bens populares, como calçados de plástico ou borracha, por exemplo, são em toda a sua cadeia de produção altamente intensivos em capital.

Por outro lado, se é verdade que o processo de industrialização é poupador de mão de obra, só a hipótese, utilizando-se o princípio da demanda efetiva, da desaceleração do ritmo de crescimento da demanda faria cair o ritmo da acumulação de capital e consequentemente do emprego como um todo. Deve-se considerar que o crescimento com elevação do nível de renda per capita e diversificação do consumo também gera empregos em setores estruturalmente mais intensivos em mão de obra, como o terciário formal e funcional.

Finalmente, ainda que seja razoável supor que haja uma relação inversa entre salário real e as condições de oferta e demanda no mercado de trabalho, esta não é certamente trivial nem automática. Ainda que um excesso de oferta permanente de mão de obra, seguindo a lógica de causalidade proposta por Furtado, pressione para baixo os salários reais, outros fatores, como estabelecimento de um salário mínimo mais ou menos elevado ou as condições políticas mais favoráveis à organização do trabalho, também desempenham um papel muito importante. Outra hipótese não explorada por Furtado é desenvolvida por Lewis (1977), em que o salário real básico depende da produtividade do setor de subsistência, por exemplo. Certamente, a leitura furtadiana parece adequada para o setor informal urbano, que absorve uma imensa massa de trabalhadores sem qualquer perspectiva de trabalho formal, exercendo uma pressão depressiva sobre a remuneração dos trabalhadores nesse setor.

\section{CONSIDERAÇÕES FINAIS}

A literatura e ideias discutidas neste trabalho cobrem um período de aproximadamente 30 anos, estendendo-se da década de 1950 até a década de 
1970. Essa temporalidade não é fruto de um recorte histórico ou analítico previamente definido neste trabalho. Ao final dos anos 1970, a América Latina e o Brasil, em particular, são varridos por uma violenta crise externa que não apenas encerrou o ciclo de crescimento acelerado iniciado nos anos 1950 como, em boa medida, interrompeu o debate sobre o próprio tema do desenvolvimento. A crise da década de 1980 e, principalmente, o fenômeno da alta inflação que se instala nessa época deslocam o debate de crescimento e perspectivas da economia a longo prazo para o efetivo curto prazo e o debate sobre estabilização econômica. Quando ocorre o retorno do Brasil ao mercado voluntário financeiro internacional, no início dos anos 1990, permitindo a estabilização da economia, o pensamento desenvolvimentista heterodoxo já se encontrava na defensiva, sofrendo os ataques da onda ideológica neoliberal internacional.

Essa inter-relação entre as ideias, as ondas ideológicas internacionais e as condições materiais historicamente determinadas dos anos 1980 acabaram por interromper não apenas o debate como a própria validação/contestação de opiniões divergentes sustentadas pelos autores heterodoxos pelo teste da realidade histórica. O Brasil foi vítima de um choque exógeno de enormes proporções que o levou à quase estagnação com alta inflação. Tal choque ocorreu de forma inteiramente independente tanto dos prognósticos negativos furtadianos sobre a interação entre composição de demanda, estrutura de oferta e concentração de renda, quanto das limitações ao ciclo endógeno encontrados nos trabalhos de maturidade de Conceição Tavares. ${ }^{24}$

A aparente reversão do ciclo ascendente neoliberal nessa entrada do século XXI vem colocando de novo as questões do desenvolvimento em posição de destaque no debate econômico, principalmente no que diz respeito ao problema do crescimento e distribuição de renda. A releitura desse debate no campo heterodoxo brasileiro torna-se um ponto importante para o avanço das ideias sem que se incorra na repetição de debates já superados no passado.

Nesse sentido, um primeiro ponto fundamental é identificar com clareza o princípio teórico básico que organiza cada interpretação sobre a acumulação de capital. Em teorias clássicas, nas quais a parcela do excedente destinada à poupança determina a velocidade da acumulação, a concentração de renda, ou seja, uma maior participação dos lucros na renda, tem um efeito 
positivo sobre o crescimento. Em uma interpretação teórica possível, seguindo o princípio da demanda efetiva, é a variação dos gastos autônomos (sejam eles o investimento autônomo ou os gastos autônomos que não criam capacidade produtiva, como consumo de duráveis, construção civil, gasto do governo e exportações) que determina a velocidade da acumulação. Uma melhora da distribuição de renda tem um efeito positivo de nível sobre o produto, do tipo once and for all através do multiplicador, mas não altera a taxa de crescimento a longo prazo. ${ }^{25}$ Uma piora da distribuição de renda, teria, então, um efeito inverso, ainda que em circunstâncias particulares, como parece ter sido o caso do início do período do milagre econômico, possa ter colaborado para compatibilizar a estrutura de oferta e demanda da economia. $\mathrm{O}$ importante é lembrar que em tais teorias os dois fenômenos são causalmente separados, podendo-se observar combinações múltiplas de crescimento alto ou baixo com maior ou menor concentração de renda.

No caso brasileiro, fica claro que o modelo de desenvolvimentismo partiu de um perfil de distribuição de renda concentrado tendo como consequência um padrão de consumo consistente com tal distribuição. Instalaram-se indústrias produtoras de certos produtos de mais elevado valor unitário, compatível com a demanda de uma fração minoritária da população que detinha, entretanto, uma parcela da renda e muito superior a tal proporção. ${ }^{26}$ Essa demanda era atendida por importações, já que a indústria instalada no Brasil se concentrava em produtos de baixo valor unitário e de baixa complexidade tecnológica. Assim, o processo de industrialização dos anos 1950 responde a uma demanda correspondente a um perfil distributivo concentrado. A industrialização, como posta em prática no Brasil, teria não apenas cristalizado esse quadro como também reproduzido de forma ampliada essa característica estrutural. Infelizmente, em um momento histórico em que se ensaiaram reformas estruturais que, talvez, pudessem interromper tal trajetória, havia forte radicalização política interna e principalmente externa, com a guerra fria atingindo seu momento mais aquecido no continente.

Não deixa de ser interessante relembrar que Tavares (1963) encerra seu ensaio construindo cenários, um dos quais repousaria no investimento autônomo governamental, mas com mudança em sua composição, com inversões no setor primário, com financiamento e estímulo ao investimento nas regiões subdesenvolvidas, de forma a elevar o emprego e a produtividade no 
"setor menos desenvolvido" e ampliar o mercado do "setor capitalista". A curto prazo seriam favorecidas as indústrias de bens de produção (que atenderiam à demanda da agricultura e das pequenas e médias indústrias das áreas subdesenvolvidas) e as indústrias tradicionais (devido ao aumento extensivo da renda no setor desenvolvido, gerado pelos investimentos que elevam a produtividade de alguns setores e pelo aumento do gasto e emprego no setor subdesenvolvido).

Anos mais tarde, algumas das propostas de Conceição Tavares ainda são atuais, ainda que a melhora de certas condições estruturais, como a expressiva elevação da produtividade do setor de produção de alimentos nos anos 1980, permita vislumbrar perspectivas redistributivistas com olhos bem mais otimistas (ver Medeiros, 2001).

Essas são questões de mais de 40 anos ainda não resolvidas. Quem sabe o recente relaxamento da restrição externa a partir de 2002 e o fim da inação intelectual dos anos 1990 não permitam finalmente à sociedade voltar a discuti-las e mesmo superá-las?

\section{NOTAS}

1. Nunca é demais lembrar que o pioneiro Furtado escreve sua obra-prima, Formação Econômica do Brasil, em Cambridge e nesta universidade frequenta seminários de todos os grandes economistas ligados a essa instituição, como Kaldor, Joan Robinson e Sraffa. Ver Furtado (1997, p. 327-332).

2. A expressão teoria clássica é usada neste artigo de forma distinta daquela encontrada na maioria dos livros-textos de macroeconomia, que usualmente apresentam o modelo de determinação do produto marginalista com a denominação de "modelo clássico". Utilizamos aqui o conceito de "economia política clássica”, “... criado por Marx, que determinava seu começo com as contribuições de Sir William Petty na Inglaterra e Pierre le Pesant de Boisguilbert e seu fim com a obra de David Ricardo e J.C.L. Simonde de Sismondi" (Aspromourgos, 1996, p. 2). A economia política clássica tem como princí pio unificador o conceito de excedente econômico. Particularmente nos interessa a noção dos autores dessa escola de que existe uma relação direta entre tal excedente econômico e a acumulação de capital. Tal noção é central no nexo causal entre poupança e investimento dos autores do desenvolvimento dos anos 1950.

3. Para uma análise do papel central da escassez de mão de obra no funcionamento do modelo neoclássico de crescimento, ver Serrano e Cesaratto (2002).

4. Em artigo de 1947, Mandelbaum destacava a presença de sobrepopulação, ocupações de baixa produtividade e de desemprego rural disfarçado nos países atrasados; em 1951, 
o relatório "Measures for the economic development of under-developed countries", elaborado por um grupo de especialistas sob o patrocínio da ONU, com a participação de Lewis, destacava o grande número de trabalhadores na agricultura que poderiam ser deslocados para outras ocupações, sem redução na produção agrícola. A esse respeito, ver Meier (1984).

5. Para Lewis, a teoria de Keynes também era inadequada, por pressupor não só oferta ilimitada de mão de obra como oferta ilimitada de capital e de terra.

6. O termo capitalista não se refere apenas ao setor privado, mas também ao estado capitalista, que pode utilizar os lucros do setor capitalista e o que conseguir extrair através de impostos do setor de subsistência para acumular capital. Também não é correto associar diretamente o setor moderno capitalista exclusivamente ao setor industrial (ver nota 7 ).

7. É importante destacar que o modelo original de Lewis não tem como hipótese central a ideia de que o setor de subsistência seja necessariamente o agrícola. Essa é uma interpretação que acabou surgindo de leituras neoclássica, como as de Fei e Ranis (1963) (ver Figueroa, 2004). Para Lewis: "Other writers, with different purposes, have made different divisions. A now popular division is between industry and agriculture, but capitalist production cannot be identified with manufacturing... The model is intended to work equally well whether the capitalists are agriculturalists or industrialists... indeed in its first version... the model presupposes that the capitalist sector is self-sufficient and contains every kind of economic activity... In the model, the noncapitalist sector serves for a time as a reservoir from which the capitalist sector draws labor" (citado por Figueroa, 2004, p. 739).

8. Não iremos discutir aqui o ponto que mais facilmente é reconhecido como a marca da Cepal, ou seja, a tendência à deterioração dos termos de troca, nem se essa impressão generalizada é acurada (para uma revisão crítica, ver Ocampo e Parra, 2007). Vale, entretanto, destacar que mesmo a tendência à deterioração dos termos de troca necessita, para sua explicação, de condições específicas no mercado de trabalho para que os frutos do progresso técnico sejam absorvidos ou não, resultando nas trajetórias distintas dos preços de bens agrícolas e industrializados. Mercados de trabalho onde há excesso de oferta de mão de obra e pouca organização trabalhista, ou seja, os mercados de trabalho dos países primário-exportadores, tendem a repassar ganhos de produtividade para os preços, reduzindo-os em face dos países produtores de bens industrializados (ver Prebisch, 1949). Lewis (1977) desenvolve um modelo de deterioração dos termos de troca em que essa relação é também resultado da evolução do salário geral da economia, que entretanto é determinado no setor de subsistência. Uma baixa produtividade nesse setor resultaria em baixos salários e deterioração dos termos de troca contra os países com tal característica. A despeito de tais considerações teóricas, Boianovsky (2007, p. 12) apresenta uma correspondência entre Furtado e Juan Noyola em que a origem comum das ideias cepalinas e de Lewis é reconhecida explicitamente por Furtado.

9. Ver Serrano (2001) para análise dessa questão.

10. É importante destacar que o consumo de luxo, como veremos elemento central no pensamento furtadiano, também já havia sido alvo de reflexão por parte de autores da teoria 
do desenvolvimento de tradição anglo-saxã. Ver Nurkse (1953), ao afirmar que: “...As grandes e crescentes diferenças entre os níveis de renda de diferentes países, aliadas a uma consciência maior do fato, podem vir a elevar a propensão geral ao consumo das nações mais pobres, a reduzir sua capacidade de poupança ... o contato e conhecimento de esquemas de consumo superiores dão asas à imaginação criando novas necessidades ... a tendência a copiar os padrões de consumo americano tende a limitar a oferta de fundos de inversão" (p. 271-272). Antes da publicação de seu trabalho mais conhecido em 1953, Nurkse apresentou em 1951 seis palestras no Rio de Janeiro, em que esse ponto foi exaustivamente analisado. Tais palestras foram alvo de uma réplica por parte de Furtado, na qual fica explícita a convergência de ideias entre os dois autores em relação ao "problema do consumo de luxo". Para um resumo de tal debate, ver Bastos (2008).

11. O desenvolvimento aqui apresentado segue Serrano (2005).

12. Como formulador de políticas aplicadas ao desenvolvimento relacionadas especificamente com o Brasil, a grande contribuição de Furtado no seu período junto à Cepal nos anos 1950 foi a redação do relatório do Grupo Misto BNDE-Cepal, "Análise e projeções do desenvolvimento econômico", em 1953. Esse relatório teria grande importância para as propostas levadas a cabo no Plano de Metas do governo JK.

13. A autora não diz a que países está se referindo, mas em outra passagem o caso dos Estados Unidos é citado.

14. A esses elementos mais estruturais da forma de constituição do processo de industrialização acrescenta Conceição Tavares o caráter regressivo das políticas públicas que não apenas não mitigam como, outrossim, potencializam a natureza excludente do processo de desenvolvimento por ela analisado.

15. Por estágio mais complexo ou avançado Furtado entende a implementação de indústrias de bens de consumo durável.

16. Não se discute aqui a diferença entre relação capital/produto efetiva e normal, a qual depende do grau de utilização da economia. Esse ponto é discutido em Tavares e Serra (1970, p. 161-162). Para uma exposição sintética desse ponto, ver Scherer (2007, p. 50-51).

17. Um dos principais elementos que levariam a essa tendência, segundo Furtado (1965), seria uma elevação do preço dos bens de capital.

18. Em Furtado (1965, p. 74-79), a fórmula para taxa de lucro r, ainda que apresentada de forma literária, é

$$
r=\left[\frac{\frac{Y}{L}-b}{\frac{K}{L}}\right]
$$

que pode ser facilmente transformada (5) dividindo-se ambos os termos da fração por L e rearranjando os seus termos.

19. Para uma revisão crítica teórica da importância da poupança forçada, ver Serrano 2001. Para uma revisão crítica da literatura brasileira bem como uma reavaliação empírica dessa hipótese, ver Bastos e Pereira (2006). 
20. O período que vai do fim do governo Kubitschek até a instalação do regime militar em 1964 é repleto de graves crises políticas que afetam diretamente as variáveis de gasto privado e público. Nesse sentido, é muito difícil distinguir, em relação à queda na taxa de crescimento do produto do início da década, os elementos normais relacionados ao funcionamento do acelerador do investimento e aqueles que são consequências da grave conjuntura sociopolítica. Para uma tentativa de integração desses dois vetores ver Melo, Bastos e Araújo (2006).

21. Lara-Resende 1982 (p. 802-803) sublinha que, sendo a política de controle do salário nominal a principal medida do plano anti-inflacionário do Paeg, as políticas restritivas implementadas após 1964 respondiam às limitações impostas pela restrição externa.

22. Para uma referência teórica desse ponto ver Serrano (2001).

23. Cárdenas, Ocampo e Thorp (2000) apresentam com muita clareza essa questão defendendo a utilização das expressões "industrialização liderada pelo Estado" ou "industrialização acelerada" como mais adequadas para descrever a experiência de desenvolvimento no pós-Segunda Guerra de alguns países latino-americanos: “... 'import substituting industrialization', ... is not a very helpful label, since it is as much about a new and expanded role of the state as it is about import substitution. ... 'Import substitution' is an imperfect label for many additional reasons. In some medium and large countries, export promotion was introduced as an essential component of the development strategy at some stage of the industrialization process, which in these cases thus became a'mixed model' that combined import substitution with export promotion.... Therefore, the essence of the [post Second World War] period ... is best expressed as 'state-led industrialization' or 'accelerated industrialization', a process accompanied by a thorough transformation of the particular economies and societies" (p. 2-3).

24. É verdade que, a despeito de suas diferenças teóricas, esses autores, no front político, se uniram na tentativa de pressionar o governo brasileiro para uma negociação mais soberana da dívida externa logo no início da crise de 1982. Como isso não ocorreu, a trajetória de inflação com estagnação era tanto, praticamente, inelutável quanto independente, como já dito, das análises que apontavam distintas restrições, ou limitações, ao padrão de industrialização brasileiro.

25. Para uma formalização simples desses pontos, ver Freitas e Serrano (2004).

26. Furtado avaliava em cerca de $5 \%$ a proporção de tal população (ver Furtado 1965, p. 59).

\section{REFERÊNCIAS BIBLIOGRÁFICAS}

ASPROMOURGOS, T. On the Origins of Classical Economics: distribution and value from William Petty to Adam Smith. Londres: Routledge, 1996.

BASTOS, C. P.; PEREIRA, B. R. Revisão crítica da hipótese da ocorrência de poupança forçada entre 1956 e 1963. In: CONGRESSO NACIONAL DE ECONOMIA POLÍTICA DA SOCIEDADE DE ECONOMIA POLÍTICA, 11. Anais. Espírito Santo, 2006. 
Guia de Leitura para o debate entre Nurkse e Furtado em 1951. Palestra na Mesa Redonda de Lançamento das Memórias do Desenvolvimento, n. 1, v. 1 acessado em 06/03/2008 www. centrocelsofurtado.org.br, 2008.

BOIANOVSKY, M. A View from the Tropics: Celso Furtado and the theory of economic development in the 1950s. In: ENCONTRO NACIONAL DE ECONOMIA DA ANPEC, 35. Anais. Recife, 2007.

CÁRDENAS, E.; OCAMPO, J. A.; THORP, R. Industrialisation and the State in Latin America: the Post War Years. An Economic History of Twentieth Century Latin America. Nova York, Palgrave Press/Martins, v. 3, 2000.

CARDOSO DE MELlO, J. M. (1975) O capitalismo tardio. 1. reimp. da 9. ed. São Paulo: Brasiliense, 1998.

CEPAL (1949) Estudo econômico da América Latina 1949. In: BIELSCHOWSKY, R. (Org.) Cinquenta anos do pensamento na Cepal. Record, v. 1, 2000.

FIGUEROA, M. Labour Market Dualism in The Model of Lewis: reply, the Manchester School, v. 72, n. 6, p. 355-359, 2004.

FREITAS, F.; SERRANO, F. Demanda efetiva e crescimento econômico. Rio de Janeiro: IE/UFRJ, 2004. (mimeo.)

FURTADO, C. Desenvolvimento e subdesenvolvimento. 2. ed. Rio de Janeiro: Fundo de Cultura, 1963.

Subdesenvolvimento e estagnação na América Latina. Rio de Janeiro: Civilização Brasileira, 1965.

—. Análise do “modelo" brasileiro. Rio de Janeiro: Civilização Brasileira, 1972.

Subdesenvolvimento e estagnação na América Latina. Rio de Janeiro: Civilização Brasileira, 1974.

- Cultura e desenvolvimento em época de crise. Rio de Janeiro: Paz e Terra, 1984.

—. A fantasia organizada. São Paulo: Paz e Terra, 1997.

- Teoria e política do desenvolvimento econômico. São Paulo: Paz e Terra, 2000.

—. Em busca de um novo modelo: reflexões sobre a crise contemporânea. Rio de Janeiro: Paz e Terra, 2002.

LARA-RESENDE, A. A política brasileira de estabilização 1963/69. Pesquisa e Planejamento Econômico, v. 12, n. 3, p. 757-806, dez. 1982.

LEWIS, W. A. (1954) O desenvolvimento econômico com oferta ilimitada de mão-de-obra. In: AGARWALA, A. N.; SINGH, S. P. (Org.). A economia do subdesenvolvimento. [S.l.]: Forense, 1969.

- The Evolution of International Economic Order. Princeton, NJ: Princeton University Press, 1977.

MEDEIROS,C. A. Desenvolvimento Econômico, Distribuição de Renda e Pobreza. In: FIORI, J. L.; MEDEIROS, C. A (Org.). Polarização mundial e crescimento. Petrópolis: Vozes, 2001. 
MEIER, G. The formative period. In: MEIER, G.; SEERS, D. Pioneers in Development. [S.1.]: Oxford University Press, 1984.

MELO H. P. DE.; BASTOS, C. P.; ARAÚJO, V. L. A política macroeconômica e o reformismo social: impasses de um governo sitiado. In: FERREIRA, M. DE M. (Org.). João Goulart: entre a memória e a história. Rio de Janeiro: FGV, 2006.

MIRANDA, J.C.; TAVARES M. C. Brasil: Estratégias de conglomeração, FIORI, J. L. (Org.). Estados e moedas no desenvolvimento das nações. Petrópolis: Editora Vozes, 1999.

NURKSE, R. Problemas de formação de capital em países subdesenvolvidos. Revista Brasileira de Economia. Re-editado em Memórias do Desenvolvimento, n. 1, ano 1, jun. 2006, Centro Internacional Celso Furtado de Políticas para o Desenvolvimento, 1951.

. (1953) Alguns aspectos internacionais do desenvolvimento econômico. In: AGARWALA, A. N.; SINGH, S. P. (Org.). [S.l.]: A economia do subdesenvolvimento. Forense, 1969.

OCAMPO, J. A.; PARRA, M. A. Half a Century of Terms of Trade Controversies. In: VERNENGO, M. E; CALDENTEY. E. P. (Org.). Ideas, Policies and Economic Devopment in the Americas, Nova York: Rutlege, 2007.

PREBISCH, R. (1949) O desenvolvimento econômico da América Latina e algum de seus problemas principais. In: BIELSCHOWSKY, R. (Org.). Cinquenta anos do pensamento na Cepal. [S.1.]: Record, 2000, v. 1.

SERRANO, F. Acumulação e gasto improdutivo na economia do desenvolvimento. In: FIORI, J. L.; MEDEIROS, C. (Orgs.). Polarização mundial e crescimento. Rio de Janeiro: Vozes, 2001. meo.)

Acumulação de capital, poupança e crescimento. Rio de Janeiro: UFRJ, 2005. (mi-

- CESARATTO, C. As leis dos rendimentos nas teorias neoclássicas do crescimento: uma crítica sraffiana. Ensaios FEE, POA, v. 23, n. 2, 2002.

SCHERER, M. P. A relação entre crescimento e distribuição de renda na economia do desenvolvimento: do modelo de Lewis à Belindia. (Dissertação de Mestrado) - Instituto de Economia da UFRJ, Rio de Janeiro, 2007.

TAVARES, M. C. (1963) Auge e declínio do processo de substituição de importações. In: TAVARES, M. C. Da substituição de importações ao capitalismo financeiro: ensaios sobre a economia brasileira. 7. ed. Rio de Janeiro: Zahar, 1978.

(1974) Acumulação de capital e industrialização no Brasil. São Paulo: Editora da Unicamp, 1985.

; Serra, J. (1970) Além da estagnação. In: TAVARES, M. C. Da substituição de importações ao capitalismo financeiro: ensaios sobre a economia brasileira. 7. ed. Rio de Janeiro: Zahar, 1978. 